\title{
Detection and enumeration of Cryptosporidium oocysts in environmental water samples by Real-time PCR assay
}

Mohammad-Reza Mahmoudi ${ }^{1}$, Mojgan Bandepour ${ }^{2,3}$, Bahram Kazemi $^{2,3}$, Asad Mirzaei ${ }^{* *}$

1. Department of Parasitology, Faculty of Medicine, Guilan University of Medical Sciences, Rasht, Iran

2. Cellular and Molecular Biology Research Center, Shahid Beheshti University of Medical Sciences, Tehran, Iran

3. Department of Biotechnology, School of Medicine, Shahid Beheshti University of Medical Sciences, Tehran, Iran

4. Department of Parasitology, Faculty of Allied Medical Sciences, Ilam University of Medical Sciences, Ilam, Iran

*Corresponding author:Tel: +98 8432227122 Fax: +98 8432227122

Address: Department of Parasitology, Faculty of Allied Medical Sciences, Ilam University of Medical Sciences, Ilam, Iran

E-mail: amirzaeii@yahoo.com

Received; 2016/12/14 revised; 2017/01/13 accepted; 2017/01/28

\section{Abstract}

Introduction: The protozoan parasite, Cryptosporidium Spp., widely spreads in both raw and drinking waters. It is the causative agents of waterborne diarrhea and gastroenteritis in the world. In the present study, a molecular assay was used for the detection and quantification of Cryptosporidium oocysts in environmental water samples.

Materials and methods: Thirty surface water samples were collected from Rasht City rivers and lagoons during 2009-2010. The samples were analysed for Cryptosporidium oocysts using Real Time PCR method. Samples were filtrated through a $1.2 \mu \mathrm{m}$ pore size cellulose nitrate membrane filter and then purified and quantified by Real-time PCR technique.

Results: Cryptosporidium oocysts were found in 19 of 30 the samples. Oocyst concentration was ranging from 0.007 to 27 oocysts per liter of the examined waters.

Conclusion: The present study showed that the investigated water supplies were contaminated by Cryptosporidium oocyst. This study indicated that in this level of oocysts there is a potential risk of waterborne cryptosporidiosis due to direct or indirect consumption of these waters by humans and animals. Real-time PCR is a technique that provides high sensitivity for detection quantitative purposes.

Keywords: Cryptosporidium spp., Water, Iran, Real-time PCR

\section{Introduction}

Cryptosporidium is one of the important agents of diarrhea and gastrointestinal disorder among children and patients with AIDS and it has been frequently responsible for waterborne outbreaks resulting from contaminated drinking water and recreational waters $(1,2)$. Ninety percent of reported outbreaks of these pathogenic protozoans occur through water, while $10 \%$ are related to food (3).
It seems that effective levels to outbreaks with these protozoa ordinarily occur when oocyst concentrations raised to 5 Giardai cyst in 100 liters of water sampled $(4,5)$ and 10 to 30 oocysts for Cryptosporidium (6). Detection of low numbers of organisms in water samples is difficult, it needs very sensitive techniques. In the past decades, conventional methods such as fluorescence labeled antibodies by immunofluorescence assays (IFA) were 
used to detect the $C$. parvum oocysts in water, but these methods have some limitations as difficulty in applying them in turbid samples and also in their need for advanced equipment for microscopically oocyst seeing. Conventional PCR techniques is the end point, therefore, it cannot be made a quantitative assessment of the copy number of parasites. But instead, quantitative Real-time PCR is capable of quantitative evaluation from early exponential phase of amplification and PCR products show that this rate is proportional to the initial DNA concentration (7-11).

IFA method is a prevalent method for the detection of Cryptosporidium in water samples. But this technique has some limitation and it is unable to species determination, so recently researchers paid more attention to molecular methods. Number of oocysts and species determination are two important factors for designation of health risk level. The small number of oocysts can cause disease in humans and the water sources are introduced as an important way of transmitting for this protozoan parasite. So, only a few studies have described a TaqMan quantitative PCR specific to Cryptosporidium (7-11). So, in present study we decided to use Real-time PCR technique for the determination and quantification of these microorganisms in water.

\section{Materials and methods}

Samples collection and filtration: Totally 30 environmental water samples were collected from surface water in Guilan province, north of Iran. Dependent to water turbidity, 2-35 liters of water were filtered. Water passes through a $142 \mathrm{~mm}$ diameter membrane filter with a pore size of $1.2 \mu \mathrm{m}$ by means of vacuum device. For the recovery of particles, the filter was rinsed by $50 \mathrm{ml}$ of $0.1 \%$ PBS-Tween 80 and particulates concentrated by centrifugation in at $3000 \mathrm{~g}$ for $10 \mathrm{~min}$. For the purification of oocysts, the pellet was subjected to sucrose-flotation according to our previously paper (12).

Genomic DNA extraction: Total DNA from samples were extracted using QIAamp DNA minikit Qiagen( $\mathrm{GmbH}$, Hilden, Germany) as recommended by Jiang et al. (2005) (13) with some modification including suspension then it was subjected to 15 freeze-thaw cycles (1 min in liquid nitrogen and $1 \mathrm{~min}$ at $65{ }^{\circ} \mathrm{C}$ per cycle).

Quantitative Real-time PCR: The Primer Design $^{\text {TM }}$ genesig Kit for Cryptosporidium (Crypto) Genomes was used for the quantification of Cryptosporidum genomes. A pair of oligonucleotide primers used for real-time PCR in this kit were designed to detect the $18 \mathrm{~S}$ rRNA gene of Cryptosporidium species, with sequences matching with $C$. hominis, $C$. parvum, $C$. meleagridis, $C$. canis and $C$. suis completely and with a single base pair (bp) mismatch at forward primer position 5 of 22 for C. felis and position 18 of 22 for C. muris (PrimerDesign Ltd). PCR mixtures were prepared according to the manufacturer's instructions. 2x Precision TM Master Mix $10 \mu$, Crypto Primer/Probe mix $1 \mu$, internal extraction control primer/probe $\operatorname{mix} 1 \mu \mathrm{l}$, RNase/DNase free water $3 \mu \mathrm{l}$ and $5 \mu \mathrm{l}$ of diluted DNA template (suggested concentration $5 \mathrm{ng} / \mu \mathrm{l})$. PCR amplification program was performed for 50 cycles' denaturation $\left(10\right.$ seconds at $\left.95^{\circ} \mathrm{C}\right)$ and data collection $\left(60\right.$ seconds at $\left.60^{\circ} \mathrm{C}\right)$.

The fractional cycle number at which realtime fluorescence signal mirrors progression of the amplification reaction over the background noise level is used as an indicator of successful target amplification. Commonly, this is called the threshold cycle (Ct) (14). All the reactions were performed in triplicate. Data were collected from the green (FAM) channel and post-run analysis performed using the Rotor gene 6000 software version 1.7 (Corbett Research)

Conversion of 18S rRNA gens number of Cryptosporidium spp. to number of 
Cryptosporidium oocysts: It has been reported that each Cryptosporidium genome in one oocyst has 20 copies of $18 \mathrm{~S}$ rRNA genes (15). Therefore, it is possible to numerate Cryptosporidium oocysts by knowing the copied numbers of $18 \mathrm{~S}$ rRNA gene in each sample. Then the copy number was converted to the number of Cryptosporidium. In the present study, accordingly the Real Time PCR data as shown in Table1 the number of oocyst were calculated based on the following formula (Log Copy number $=(\mathrm{CT}$ single copy - CTS)/Slop).

\section{Results}

Altogether, 30 surface water samples from Rasht city (Guilan Province North of Iran) rivers were collected and Cryptosporidium oocysts were successfully quantified. 19 out of 30 samples were positive by Real Time PCR. Oocyst concentration was ranging from 0.007 to 27 in different samples. The lowest number of Oocyst belongs to Zarjoob and highest number to Goharrood River (Table 1).

Table 1. Number of oocyst detected in water samples by Real Time PCR.

\begin{tabular}{lcccc}
\hline River name & ${\text { Mean } \mathbf{C}_{\mathbf{T}}{ }^{*}}$ & $\mathbf{C}_{\mathbf{T}}$ Single copy & Copy number & Oocysts per litter \\
\hline Zar-Joob & 31.855 & 39.72 & 5.893 & 1 \\
Zar- Joob & 19.525 & 39.72 & 27.372 & 2 \\
Zar- Joob & 36.255 & 39.72 & 0.806 & 0.2 \\
Zar- Joob & 19.025 & 39.72 & 28.745 & 4.5 \\
Zar- Joob & 15.91 & 40.33 & 51.891 & 0.08 \\
Gohar-Rood & 34.91 & 40.33 & 2.556 & 0.28 \\
Gohar-Rood & 30.145 & 40.33 & 9.027 & 4.87 \\
Zar- Joob & 10.375 & 40.33 & 78.080 & 0.6 \\
Gohar-rood & 29.895 & 38.45 & 6.294 & 0.25 \\
Zar- Joob & 33.6 & 38.45 & 2.023 & 0.1 \\
Gohar-rood & 34.54 & 38.4 & 1.281 & 0.31 \\
Zar- Joob & 33.095 & 38.45 & 2.466 & 3 \\
Zar- Joob & 18.04 & 38.45 & 35.824 & 1 \\
Zar- Joob & 30.77 & 38.45 & 5.072 & 1 \\
Zar- Joob & 30.37 & 38.45 & 5.615 & 10 \\
Eynak lagon & 19.97 & 38.89 & 30.250 & 27 \\
Gohar-Rood & 13.53 & 38.89 & 54.348 & 8.5 \\
Zar- Joob & 18.585 & 38.89 & 34.841 & 18 \\
Eynak lagon & 17.985 & 38.89 & 36.930 & 0.007 \\
Zar- Joob & 37.765 & 38.89 & 0.107 & 0.11 \\
Zar- Joob & 34.8 & 38.89 & 1.414 & 0.16 \\
Gohar-Rood & 33.035 & 38.89 & 2.897 & \\
\hline Concentran & & & & \\
\hline
\end{tabular}

*Concentration

\section{Discussion}

The oocysts, infectious form of protozoa, are very resistant to stresses such as desiccation and disinfectant materials (chlorine) they can remain infectious for a long time in the environment (16). The human ID50 of 30 oocysts reported for Cryptosporidium parvum (17). There have been several studies about Cryptosporidium in different parts of Iran. The prevalence in children has been reported to be 2.5 to $10.4 \%(18,19)$ and in HIV patients in Iran was reported to be
$1.5 \%$ to $9.4 \%(20-22)$. The prevalence of Cryptosporidium in cattle from different regions of Iran were $1.61 \%$ to $18.8 \%$ 25).

There are many studies that only qualified Cryptosporidium in Iranian surface water by PCR-RFLP method $(26,27)$. In our previously study Cryptosporidium was detected by IFA nested PCR and LAMP methods in water samples (28).

It seems that effective levels to outbreaks with Cryptosporidium ordinarily occur 
when oocyst concentrations raised to 10 to 30 oocyst in 100 liters of water sampled (6). So, detection and quantification of low numbers of organism is difficult and needs high sensitive techniques.

It should be noted that this is the first study performed in Iran for the detection and enumeration of Cryptosporidium in water supply by Real Time method. In the present study, 19 out of 30 samples were positive by Real Time PCR. This high prevalence was similar to other countries which are from 60 to $96 \%$ in the United States $(29,30)$ and from 20 to $64 \%$ in Canada (31).

In addition to the identification of oocysts in water, the concentration of oocysts in water samples is helpful to design a program for health management and protection of water resources. In this study, the concentration of oocysts in surface waters was determined to be 0.007 to 27 per liter (Table 1). The lowest concentration belongs to Zarjoob and the highest to Gohar Rood River, Rasht, Guilan, Iran.

Zarjoob River was more polluted than Gohar Rood River (Table1). It may due to more entrance of urban and industrial sewage of Rasht city to Zarjoob River.

Low numbers of oocysts have been reported in some other studies in other countries $(29,32,33)$ There levels in surface

\section{References}

1. Mac Kenzie WR, Hoxie NJ, Proctor ME, Gradus MS, Blair KA, Peterson $\mathrm{DE}$, et al. A massive outbreak in Milwaukee of cryptosporidium infection transmitted through the public water supply. N Engl J Med. 1994; 331(3):161-7.

2. Hlavsa MC, Watson JC, Beach MJ. Cryptosporidiosis surveillance-United States 1999-2002. MMWR Surveill Summ. 2005; 54:1-8.

3. Rose JB, Slifko TR. Giardia, Cryptosporidium, and Cyclospora and waters are very low, ranging from 0.5 to 5,000 organisms in 100 liters of water (31, 34-37).

Although it may be a relatively low number of oocysts in water samples, but relatively infectious dose is low too and even as low as 1 oocysts can cause infection (17). So there is a potential risk of waterborne cryptosporidiosis due to direct or indirect consumption of these rivers specially Zarjoob river by humans and animals.

\section{Conclusion}

Although our detection and quantification of low numbers of organisms is difficult but in the present study, Cryptosporidium oocysts successfully enumerated by Real Time PCR. So we can use this technique for the quantification of Cryptosporidium in water samples especially in samples with low number of oocysts that requires very sensitive techniques.

\section{Acknowledgment}

This paper was extracted form Mohammad-Reza Mahmoudi`s PhD thesis and supported by Vice Chancellor in Research Affair of Shahid Beheshti University of Medical Sciences (through grant number: 89-01-91-7138).

their impact on foods: a review. J Food Prot. 1999; 62(9):1059-70.

4. Guy RA, Payment P, Krull UJ, Horgen PA. Real-Time PCR for Quantification of Giardia and Cryptosporid in Environmental Water Samples and Sewage. Appl Environ Microbiol. 2003; 69(9):5178-85.

5. Wallis PM, Matson D, Jones $M$, Jamieson J. Application of monitoring data for Giardia and Cryptosporidium to boil water advisories. Risk Anal. 2001; 21(6):1077-85. 
6. Hass CN, Rose JB. Developing an action level for Cryptosporidium. Am Water Works Assoc. 1995; 87(9):81-4.

7. Higgins JA, Fayer R, Trout JM, Xiao L, Lal AA, Kerby S, et al. Real-time PCR for the detection of Cryptosporidium parvum. J Microbiol Methods. 2001; 47(3):323-37.

8. Limor JR, Lal AA, Xiao L. Detection and differentiation of Cryptosporidium parasites that are pathogenic for humans by real-time PCR. J Clin Microbiol. 2002; 40(7):2335-8.

9. Guy RA, Payment P, Krull UJ, Horgen PA. Real-time PCR for quantification of Giardia and Cryptosporidium in environmental water samples and sewage. Appl Environ Microbiol. 2003; 69(9):5178-85.

10. Keegan AR, Fanok S, Monis PT, Saint CP. Cell culture-Taqman PCR assay for evaluation of Cryptosporidium parvum disinfection. Appl Environ Microbiol. 2003; 69(5):2505-11.

11. Fontaine M, Guillot E. An immunomagnetic separation-real-time PCR method for quantification of Cryptosporidium parvum in water samples. J Microbiol Methods. 2003; 54(1):29-36.

12. Mahmoudi M, Ashrafi K, Abedinzadeh H, Tahvildar-Bideruni F, Haghighi A, Bandehpour M, et al. Development of sensitive detection of cryptosporidium and giardia from surface water in iran. Iran J Parasitol. 2011; 6(3):43-51.

13. Jiang J, Alderisio KA, Singh A, Xiao L. Development of procedures for direct extraction of Cryptosporidium DNA from water concentrates and for relief of PCR inhibitors. Appl Environ Microbiol. 2005; 71(3):1135-41.

14. Wilhelm J, Pingoud A, Hahn M. Comparison between Taq DNA polymerase and its Stoffel fragment for quantitative real time PCR. Biotechniques. 2001; 30(5):1052-6.

15. Abrahamsen MS, Templeton TJ, Enomoto S, Abrahante JE, Zhu G, Lancto CA, et al. Complete genome sequence of the apicomplexan, Cryptosporidium parvum. Science. 2004; 304(5669):441-5.

16. Robertson LJ, Campbell AT, Smith HV. Survival of Cryptosporidium parvum oocysts under various environmental pressures. Appl Environ Microbiol. 1992; 58(11):3494-500.

17. DuPont HL, Chappell CL, Sterling CR, Okhuysen PC, Rose JB, Jakubowski W. The infectivity of Cryptosporidium parvum in healthy volunteers. N Engl J Med. 1995; 332(13):855-9.

18. Nazemalhosseini-Mojarad E, Haghighib A, Taghipour N, Keshavarz A, Reza Mohebi S, Zali M, et al. Subtype analysis of Cryptosporidium parvum and Cryptosporidium hominis isolates from humans and cattle in Iran. Vet Parasitol. 2011; 179(1-3):250-2.

19. Moghaddam AA. Symptomatic and asymptomatic cryptosporidiosis in young children in Iran. Pak J Biol Sci. 2007; 10(7):1108-12.

20. Meamar AR, Rezaian M, Mohraz M, Hadighi R, Kia EB. Concomitant severe infection with Cryptosporidium parvum and Hymenolepis nana in an AIDS patient. Indian J Med Sci. 2007; 61(7):418-9.

21. Nahrevanian $H, \quad$ Assmar $M$. Cryptosporidiosis in immunocompromised patients in the Islamic Republic of Iran. J Microbiol Immunol Infect. 2008; 41(1):74-7.

22. Daryani A, Sharif M, Meigouni M, Mahmoudi FB, Rafiei A, Gholami Sh, et al. Prevalence of intestinal parasites and profile of $\mathrm{CD} 4+$ counts in HIV+/AIDS people in north of Iran, 2007-2008. Pak J Biol Sci. 2009; 12(18):1277-81.

23. Fallah E, Mahdavi Poor B, Jamali R, Hatam Nahavandi K, Asgharzadeh M. Molecular characterization of cryptosporidium isolates from cattle in a slaughterhouse in Tabriz, Northwestern Iran. J Biol Sci. 2008; 8(3):639-43. 
24. Keshavarz A, Haghighi A, Athari A, Kazemi B, Abadi A, Mojarad EN. Prevalence and molecular characterization of bovine Cryptosporidium in Qazvin province, Iran. Vet Parasitol. 2009; 160(34):316-8.

25. Azami M. Prevalence of Cryptosporidium infection in cattle in Isfahan, Iran. J Eukaryot Microbiol. 2007; 54(1):100-2.

26. Manouchehri Naeini K, Asadi M, Hashemzade Chaleshtor M. Detection and molecular characterization of Cryptosporidium species in recreational waters of Chaharmahal va Bakhtiyari Province of Iran using nested-PCR-RFLP. Iran J Parasitol. 2010; 6(1):20-7.

27. Mohammadi Ghalebin B, Fallah E, Asgharzadh M, Hassan Kazemi A, Arzanlou M. Detection and Identification of Cryptosporidium species in Water Samples from a River in Ardabil City, Northwestern Iran. Res J Biol Sci. 2007; 2(4):498-502.

28. Mahmoudi MR, Kazemi B, Mohammadiha A, Mirzaei A, Karanis P. Detection of Cryptosporidium and Giardia (oo)cysts by IFA, PCR and LAMP in surface water from Rasht, Iran. Trans R Soc Trop Med Hyg. 2013; 107(8):511-7.

29. Ongerth JE, Stibbs HH. Identification of Cryptosporidium oocysts in river water. Appl Environ Microbiol. 1987; 53(4):672-6.

30. LeChevallier MW, Norton WD, Lee RG. Occurrence of Giardia and Cryptosporidium spp. in surface water supplies. Appl Environ Microbiol. 1991; 57(9):2610-6.
31. Wallis PM, Erlandsen SL, IsaacRenton JL, Olson ME, Robertson WJ, van Keulen H. Prevalence of Giardia cysts and Cryptosporidium oocysts and characterization of Giardia spp. isolated from drinking water in Canada. Appl Environ Microbiol. 1996; 62(8):2789-97.

32. LeChevallier MW, Norton WD, Lee RG. Giardia and Cryptosporidium spp. in filtered drinking water supplies. Appl Environ Microbiol. 1991; 57(9):2617-21.

33. Azman J, Init I, Wan Yusoff WS. Occurrence of Giardia and Cryptosporidium (oo)cysts in the river water of two recreational areas in Selangor, Malaysia. Trop Biomed. 2009; 26(3):289-302.

34. Isaac-Renton JL, Moorehead W, Ross A. Longitudinal studies of Giardia contamination in two community drinking water supplies: cyst levels, parasite viability, and health impact. Appl Environ Microbiol. 1996; 62:4754.

35. Ongerath JE, Hunter GD, DeWalle FB. Watershed use and Giardia cyst presence. Water Res. 1995; 29(5):1295-9.

36. Ong C, Moorehead W, Ross A, IsaacRenton J. Studies of Giardia spp. and Cryptosporidium spp. in two adjacent watersheds. Appl Environ Microbiol. 1996; 62(8):2798-805.

37. Payment P, Berte A, Prevost M, Menard B, Barbeau B. Occurrence of pathogenic microorganisms in the Saint Lawrence River (Canada) and comparison of health risks for populations using it as their source of drinking water. Can J Microbiol. 2000; 46(6):565-76. 